\title{
Teaching metacognition in clinical decision-making using a novel mnemonic checklist: an exploratory study
}

\author{
Keng Sheng Chew $^{1}$, MD, MMed, Steven J Durning ${ }^{2}$, MD, PhD, Jeroen JG van Merriënboer ${ }^{3}$, PhD
}

INTRODUCTION Metacognition is a cognitive debiasing strategy that clinicians can use to deliberately detach themselves from the immediate context of a clinical decision, which allows them to reflect upon the thinking process. However, cognitive debiasing strategies are often most needed when the clinician cannot afford the time to use them. A mnemonic checklist known as TWED ( $T$ = threat, $W=$ what else, $E=$ evidence and $D=$ dispositional factors) was recently created to facilitate metacognition. This study explores the hypothesis that the TWED checklist improves the ability of medical students to make better clinical decisions.

METHODS Two groups of final-year medical students from Universiti Sains Malaysia, Malaysia, were recruited to participate in this quasi-experimental study. The intervention group $(n=21)$ received educational intervention that introduced the TWED checklist, while the control group $(n=19)$ received a tutorial on basic electrocardiography. Post-intervention, both groups received a similar assessment on clinical decision-making based on five case scenarios.

RESULTS The mean score of the intervention group was significantly higher than that of the control group (18.50 \pm 4.45 marks vs. $12.50 \pm 2.84$ marks, $p<0.001)$. In three of the five case scenarios, students in the intervention group obtained higher scores than those in the control group.

CONCLUSION The results of this study support the use of the TWED checklist to facilitate metacognition in clinical decision-making.

Keywords: checklist, cognitive bias, cognitive debiasing strategy, medical education, metacognition

\section{INTRODUCTION}

According to the dual process theory, there are two types of decision-making - Types 1 and 2.(1-5) The defining feature of Type 1 is automaticity, which facilitates fast decision-making independent of higher-level control. ${ }^{(4,5)}$ The defining feature of Type 2 is cognitive decoupling, which involves the analytical ability to compare and contrast alternatives using imagination before making a decision. ${ }^{(4,5)}$

Clinical decision-making is a complex process involving interaction between Type 1 and Type 2 processes. ${ }^{(1,6,7)}$ Type 1 decision-making results in fast and accurate clinical decisions, particularly if the decision-maker is an experienced clinician who is armed with the necessary knowledge, skills and experience (collectively known as 'mindware'). ${ }^{(8)}$ However, it is more affected by cognitive biases than Type $2 .^{(6,9)}$ Cognitive biases, defined as deviations from rationality, ${ }^{(10)}$ may derail clinicians into making medical errors if they go unchecked. ${ }^{(9)}$ Numerous cognitive biases have been identified, including availability bias, anchoring, confirmation bias and search satisficing. ${ }^{(11)} \mathrm{A}$ brief description of these common cognitive biases is given in Table I.

Many strategies to reduce cognitive biases (i.e. debias) have been proposed. ${ }^{(11-13)}$ A common denominator undergirding these strategies is critical self-reflection with a heightened sense of vigilance. ${ }^{(9,12)}$ Metacognitive regulation (i.e. thinking about thinking) is one such strategy; it is defined as the ability to deliberately detach oneself from the immediate context in which the decision is made in order to reflect on the thinking process used. ${ }^{(11,12)}$ Metacognition allows one to check for conflicting evidence and consider alternatives to the decisions made. ${ }^{(12)}$

However, cognitive debiasing is easy in theory yet difficult in practice. ${ }^{(11,14,15)}$ Generally, pessimism still prevails on how best to put debiasing strategies into practice..$^{(9,11,15)}$ This challenge is particularly germane to clinical decision-making in a stressful environment such as the emergency department. ${ }^{(16)}$ Clinicians may be more likely to use Type 1 decision-making when they are busy, ${ }^{(3)}$ as it allows them to make swift, automatic and reflexive decisions. Furthermore, many of these cognitive debiasing strategies take time and slow down the entire clinical decisionmaking process; hence, they may be ineffective in reducing medical errors. ${ }^{(17)}$ When the emergency department is not operating under stressful conditions, the clinicians theoretically have more time to analyse the situation critically to ensure that nothing of importance is missed, and vice versa. This is paradoxical, as cognitive debiasing strategies are most needed in stressful environments. Therefore, it has been theorised that the process used to effectively debias cognitive biases (which occur more commonly in Type 1 thinking) should be a Type 1 thinking process; that is, the strategy must be easily retrievable and automatised to a large degree in a stressful environment.

The TWED checklist (Fig. 1), a novel innovation that was recently created, is a mnemonic checklist designed to help reduce cognitive bias. Its four letters stand for threat ("Is there any lifeor-limb threat that I need to rule out in this patient?"), what else ("What if I am wrong? What else could it be?"), evidence ("Do I

${ }^{1}$ Formerly from the School of Medical Sciences, Universiti Sains Malaysia, Malaysia, ${ }^{2}$ Uniformed Services University of the Health Sciences, Bethesda, Maryland, USA, ${ }^{3}$ School of Health Education, Maastricht University, Maastricht, the Netherlands

Correspondence: Dr Chew Keng Sheng, Professor, Faculty of Medicine and Health Sciences, Universiti Malaysia Sarawak, Jln Meranti, 94300 Kota Samarahan, Sarawak, Malaysia.cksheng74@gmail.com 
Table I. Common cognitive biases in clinical medicine.

\begin{tabular}{ll}
\hline Cognitive bias & Description \\
\hline Availability bias & $\begin{array}{l}\text { The tendency of clinicians to judge things as being more likely, or frequently occurring, if they readily come to } \\
\text { mind. }{ }^{(11)} \text { For example, if a clinician has a recent experience with thoracic aortic dissection, the clinician may be } \\
\text { more likely to diagnose this disease in a patient who presents with chest pain. }\end{array}$ \\
& $\begin{array}{l}\text { The tendency of clinicians to fixate their perception on the salient features of a patient's initial presentation at } \\
\text { an early point of the diagnostic process, such that they fail to adjust their initial impression even in light of later } \\
\text { relevant information. }\end{array}$ \\
Confirmation bias & $\begin{array}{l}\text { The tendency of clinicians to look for confirming evidence to support the diagnosis they are 'anchoring' to, while } \\
\text { downplaying, ignoring or not actively seeking evidence that may point to the contrary. }\end{array}$ \\
Search satisficing & $\begin{array}{l}\text { The tendency of clinicians to stop looking or to call off a search for a second diagnosis when they have found the } \\
\text { first one. This bias can be detrimental in polytrauma cases. }\end{array}$
\end{tabular}

\begin{tabular}{|c|c|}
\hline $\begin{array}{l}\text { T = life-or-limb threat (What are the threatening conditions in this } \\
\text { patient?) } \\
\text { Rationale: } \\
\text { This quadrant encapsulates the ROWS (rule out worst-case } \\
\text { scenarios) heuristic as a cognitive-forcing strategy as well as to } \\
\text { debias anchoring and triage cueing. }\end{array}$ & $\begin{array}{l}\text { W = wrong? (What if I am wrong? What else could it be?) } \\
\text { Rationale: } \\
\text { To debias search satisficing, anchoring, confirmation, availability } \\
\text { biases, etc. }\end{array}$ \\
\hline $\begin{array}{l}\text { E = evidence (Do I have sufficient evidence for or to exclude this } \\
\text { diagnosis?) } \\
\text { Rationale: } \\
\text { To debias anchoring, confirmation bias, blind spot, myside bias, ego } \\
\text { bias, etc. }\end{array}$ & $\begin{array}{l}\text { D = dispositional factors (What are the environmental and } \\
\text { emotional dispositions influencing my decision?) } \\
\text { Rationale: } \\
\text { These dispositional factors may affect our decision-making. } \\
\text { E.g. environmental - chaotic, busy working place; } \\
\text { emotional - sleepiness, tiredness, anger. }\end{array}$ \\
\hline
\end{tabular}

Fig. 1 Diagram shows the TWED checklist and the potential cognitive biases it addresses.

have sufficient evidence to support or exclude this diagnosis?") and dispositional factors ("Is there any dispositional factor that affects my decision?"). Dispositional factors consist of two E's: (a) environmental factors (e.g. a stressful clinical setting); and (b) emotional factors (e.g. fatigue and anger). These two factors have been shown to affect the frequency of cognitive biases among clinicians.

The present study aimed to test the hypothesis that the TWED checklist facilitates metacognition among medical students so that they can make better-quality clinical decisions. This was measured by the ability of the students to generate a second, more serious diagnosis and their ability to decide on appropriate investigations and management plans.

\section{METHODS}

This study was approved by the Research Ethics Committee of Universiti Sains Malaysia, Malaysia. Two groups of final-year (i.e. Year 5) medical students from the Universiti Sains Malaysia class of 2013/14 were selected for this quasi-experimental study. The intervention group $(n=21)$ received educational intervention that consisted of a 90-minute tutorial on cognitive biases and debiasing strategies. The tutorial included an introduction to the dual-process theory of thinking, and a discussion on various common cognitive biases, cognitive debiasing strategies and the TWED checklist. The students in the intervention group were also given a demonstration of how to apply the TWED checklist in clinical cases. During the tutorial, the tutors emphasised that the TWED checklist is not an instantaneous solution and requires repetitive practice in a clinical setting. The control group $(n=19)$ was not exposed to this educational intervention. Instead, they received a 90-minute tutorial on basic electrocardiography.

A set of five clinical case scenarios was used as the assessment tool for this study. These case scenarios were designed to test the students' ability to look beyond apparent diagnoses to generate alternative hypotheses or diagnoses. The cases were framed to lead the students to make an obvious diagnosis that was not necessarily incorrect, but was not the critical diagnosis. Apart from the clinical signs that pointed toward the obvious diagnosis in each case, other subtle clinical cues indicated the likelihood of a more urgent or life-threatening diagnosis that should be considered. In real-life situations, the failure to consider these diagnoses may be detrimental to the patient. Common potential cognitive biases were embedded in each case: availability bias in Cases 2, 3 and 4; anchoring in Case 4; confirmation bias in Cases 4 and 5; and search satisficing in all five cases.

Undergirding the construction of these cases was the theoretical notion that the students would be more likely to pick up on the alternative diagnoses if they reflected on the questions posed in the TWED checklist. Each case scenario had 2-3 questions, one question testing their ability to generate alternative diagnoses that should be considered and 1-2 questions testing their ability to make decisions on various management aspects of the case (e.g. whether certain investigations or treatment modalities were required, and whether the patient should be discharged). The maximum marks allotted to each question were made known to the students. Detailed descriptions of the objectives of the five cases, the embedded cognitive biases and how the TWED checklist can help to promote metacognition are shown in Appendix 1. 
Table II. Comparison of the mean scores of the intervention $(n=21)$ and control $(n=19)$ groups for Cases $1,2,3$ and 5 .

\begin{tabular}{|c|c|c|c|c|c|c|c|c|}
\hline \multirow[t]{2}{*}{ Case } & \multicolumn{2}{|c|}{ Mean \pm standard deviation } & \multirow{2}{*}{$\begin{array}{c}\text { Mean } \\
\text { difference }\end{array}$} & \multirow[t]{2}{*}{$95 \% \mathrm{Cl}$} & \multirow[t]{2}{*}{$t(\mathrm{df})$} & \multirow[t]{2}{*}{ p-value } & \multicolumn{2}{|c|}{ ICC } \\
\hline & $\begin{array}{l}\text { Intervention } \\
\text { group }\end{array}$ & $\begin{array}{c}\text { Control } \\
\text { group }\end{array}$ & & & & & $\begin{array}{l}\text { Intervention } \\
\text { group }\end{array}$ & $\begin{array}{l}\text { Control } \\
\text { group }\end{array}$ \\
\hline 1 & $4.55 \pm 1.45$ & $2.21 \pm 0.86$ & 2.34 & 1.55 to 3.12 & $t(38)=6.021$ & $<0.001$ & 0.85 & 0.80 \\
\hline 2 & $3.53 \pm 1.85$ & $3.16 \pm 1.31$ & 0.37 & -0.67 to 1.40 & $t(38)=0.713$ & 0.48 & 0.91 & 0.75 \\
\hline 3 & $4.07 \pm 1.16$ & $2.24 \pm 0.79$ & 1.83 & 1.19 to 2.47 & $t(38)=5.77$ & $<0.001$ & 0.45 & 0.68 \\
\hline 5 & $4.07 \pm 1.30$ & $2.81 \pm 1.06$ & 1.26 & 0.49 to 2.01 & $t(38)=3.33$ & 0.002 & 0.60 & 0.58 \\
\hline
\end{tabular}

The maximum score for all the cases was 10. Independent $t$-test was used for the analysis of mean scores between the two groups, as normality of distribution was assumed. Equality of variances was assumed based on the parametric Levene's test for homogeneity of variance $(p>0.05)$. The critical value for $t$-statistic at two-tailed $\alpha=0.05$ was 2.024. Intra-class correlation coefficient (ICC) was calculated using average measures and a two-way mixed model with absolute agreement. $\mathrm{Cl}$ : confidence interval; df: degrees of freedom

Table III. Comparison of the mean ranks of both the intervention and control groups for Case 4 using the Mann-Whitney $U$ test.

\begin{tabular}{|c|c|c|c|c|c|c|c|}
\hline Group & Median \pm SD & Mean rank & Sum of ranks & $U$-value & z-statistics & $p$-value & ICC \\
\hline Case 4 & & & & 144 & -1.58 & 0.114 & \\
\hline Intervention $(n=21)$ & $2.28 \pm 0.70$ & 23.14 & 486 & & & & 0.64 \\
\hline Control $(n=19)$ & $2.08 \pm 0.51$ & 17.58 & 334 & & & & 0.46 \\
\hline
\end{tabular}

The maximum score for Case 4 was 10. Mann-Whitney $U$ test was used, as the normality of distribution could not be assumed for Case 4 (Shapiro-Wilk test, $p=0.01$ ). Equality of variances assumed based on non-parametric Levene's test for homogeneity of variance $(p>0.05)$. The critical $U$-value at two-tailed $\alpha=0.05$ was 126 . The obtained U-value in Case 4 was 144, more than the critical U-value (i.e. 126); thus, the null hypothesis was not rejected. Intra-class correlation coefficient (ICC) was calculated using average measures and a two-way mixed model with absolute agreement. SD: standard deviation

During the first week of their emergency medicine posting, the intervention group received a 90-minute tutorial on cognitive biases and debiasing strategies (i.e. the educational intervention), while the control group received a 90-minute tutorial on basic electrocardiography interpretation. Two weeks later, the students in both groups were asked to independently and anonymously complete the test on the five case scenarios. Students in the intervention group were asked to think about their initial impressions or diagnoses before reflecting on the questions in the TWED checklist. A quiz, in the form of 20 true/false factual recall questions, was administered to both groups before they started on the test. This was immediately followed by feedback on the correct answers, although the quiz was not scored. The purpose of the quiz was to ensure that the students had the necessary knowledge to answer the questions in the case scenarios. For example, to ascertain that the students had the necessary knowledge to answer Case 1 (Appendix 2), the quiz contained a mixture of related and unrelated toxicology questions (e.g. questions on the manifestations of cholinergic, anticholinergic, sympathomimetic and opioid toxidromes). To simulate a time-pressured, stressful environment and possibly improve the external validity of the study, the students were instructed to allocate only ten minutes to each case. As participation was voluntary, the students were told that they were free to opt out if so desired. To ensure that students from the control group also benefited from the study, feedback was given after they completed the case scenarios.

The students' responses were evaluated by two assessors who were both emergency physicians and senior lecturers. These assessors performed their evaluations independently, using a marking scheme that was provided, and were blinded to the other's assessment of the students and the group the students belonged to. The average of the marks awarded by the two assessors was used for statistical analysis. In the event that the students gave alternative diagnoses that were not listed in the marking scheme, the assessors used their discretion to decide whether marks should be rewarded (Appendix 2).

\section{RESULTS}

The results had good interrater agreement, with intra-class correlation coefficients of 0.93 for Case 1, 0.86 for Case 2, 0.76 for Case 3, 0.45 for Case 4 and 0.70 for Case 5. Overall, students in the intervention group scored higher in all five cases than those in the control group. An independent $t$-test (parametric data with z-values within \pm 1.96 for kurtosis and skewness; $p>0.05$ in Shapiro-Wilk test) comparing the aggregate mean scores of the students in all the five cases showed that the intervention group (mean: $18.50 \pm 4.45$ marks, max: 50 marks) scored significantly higher than the control group (mean: $12.50 \pm 2.84$ marks, max: 50 marks; $t[38]=5.01, \mathrm{p}<0.001)$. As the $t$-statistic value was greater than the critical value at a two-tailed alpha of 0.05 (i.e. 2.024), the null hypothesis was rejected. Detailed comparisons of the scores for each case are shown in Tables II and III. In three of the five cases, students in the intervention group were able to make better-quality clinical decisions than those in the control group.

\section{DISCUSSION}

The results of this study showed that educational intervention in the form of a 90-minute tutorial on cognitive biases and debiasing strategies, including introducing the TWED checklist, improves the ability of medical students to make clinical decisions. Although clinicians may try to avoid committing diagnostic errors that result from cognitive biases, this intention may not translate into an executable goal. To bridge the gap between goal intention and required action, Gollwitzer conceptualised the idea of the implementation intention. ${ }^{(18)}$ An implementation intention is not 


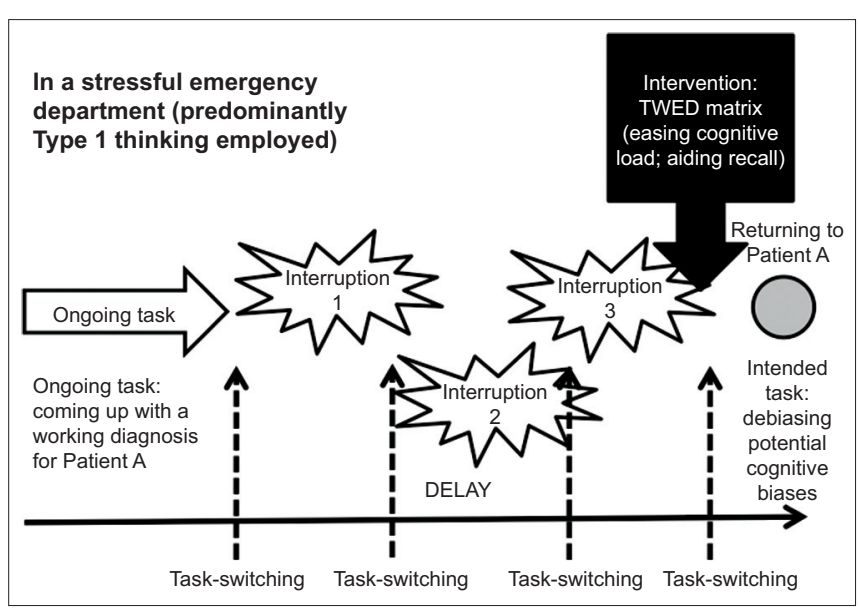

Fig. 2 Diagram shows the difficulties of applying cognitive debiasing strategies in a chaotic emergency department and the point at which the TWED checklist can be applied.

the same as a goal intention; it is a predecided measure that allows the automatisation of goal intentions even in unfavourable environments (e.g. a busy and stressful environment). For example, if the intended goal is to minimise diagnostic errors secondary to cognitive biases, the implementation intention could be the use of a mnemonic checklist, like the TWED checklist, which is memorable and easily retrievable.

In a favourable clinical environment, metacognition can be executed with relative ease, as the clinician can afford the time and effort to do so. However, interruptions are ubiquitous in emergency departments. These interruptions often delay clinicians from executing their intention to recalibrate their thinking. ${ }^{(19)}$ Interruptions impose an additional burden on the cognitive load of clinicians, as they have to switch from one task to another. ${ }^{(19)}$ By the time they return to attend to their first patient after having addressed numerous interruptions, they might be distracted and forget to execute their intention. It must also be emphasised that performing cognitive debiasing does not necessarily translate into eventual improvement in diagnostic accuracy. ${ }^{(17)}$ In fact, in some cases, the contrary can be true. ${ }^{(17}$ Gathering more data may slow down the entire decision-making process unnecessarily, which can be detrimental at times when emergency interventions such as cardiopulmonary resuscitation are urgently called for. This is especially the case if the process of recalling the numerous cognitive biases, identifying the cognitive biases involved and picking the right cognitive debiasing strategy is taxing to working memory.

In this regard, a mnemonic checklist such as the TWED checklist can help clinicians to perform cognitive debiasing after having addressed numerous interruptions (Fig. 2), since it helps to facilitate recall(20) by transforming the technical terms of common cognitive biases into a memorable acronym. To be effective, the checklist should be applied after a decision is made rather than before or during the decision-making process. ${ }^{(21)}$ This is because upfront application of a checklist increases the cognitive load of the decision-maker. ${ }^{(21)}$ Furthermore, the TWED checklist can only be meaningfully applied after an initial clinical decision has been made, due to the nature of its questions. Similar to applying the brakes in the fast lane of clinical decision-making, the TWED checklist affords the clinician an opportunity to reflect on the quality of the decision made before moving on to the next case.

The present study employed a quasi-experimental design. Although this may have weakened the internal validity of the data, we can expect the knowledge and experience of the students in both groups to be similar, as they were selected sequentially at the beginning of their Year 5 semester with four years of undergraduate experience. Additionally, all students who had progressed to Year 5 would have passed their clinical rotations when they were in Year 4 and thus met the minimum standard expected of them. Their clinical rotations included internal medicine, surgery, obstetrics and gynaecology, paediatrics, orthopaedics, and neurology and neurosurgery.

Four other pertinent limitations need to be addressed in future research on the TWED checklist. First, the methodology of the present study was not designed to objectively demonstrate that the TWED checklist had been successfully used as a cognitive debiasing strategy. Conducting direct laboratory studies on the effects of cognitive debiasing strategies is extremely challenging, as it cannot be ascertained whether any of the cognitive biases were committed by the study participants. Only the decisionmakers would know if they had committed cognitive biases in their train of thought; even for those who had, admitting to it is highly subjective and contingent to the individual's awareness of cognitive biases during the decision-making process. ${ }^{(17)}$ Secondly, the Hawthorne effect should be taken into consideration. ${ }^{(22)}$ The fact that students were aware that they were being observed on how they made decisions after a tutorial session would have alerted them to possible 'traps' in case scenarios. The challenge, therefore, is to investigate whether using the TWED checklist makes a difference in real-time clinical settings where the decision-maker is not being observed. Third, no matter how vigorous the study's methodology, any research conducted in a classroom setting lacks the ecological validity of a complex clinical setting. ${ }^{(6)}$ Mimicking the real ambient environment of a stressful clinical setting is perhaps the greatest challenge faced by researchers who seek to study cognitive biases. ${ }^{(6)}$ Finally, the present study merely uses one educational intervention. It is unlikely that a one-time educational intervention with cognitive debiasing strategies is effective over a long period of time. ${ }^{(9)}$ People are likely to forget. To be skilled practitioners of the TWED checklist, repetitive practice is needed. Clinical decision-making is a complex process; experience, expertise and the necessary mindware affect the quality of the decision.

The question remains whether the TWED checklist should be used as a 'cognitive screening tool' for every single clinical decision that clinicians make. McDaniel et al theorised that constant, prolonged exposure to a mnemonic cue offers no advantage (in aiding memory to execute intended actions) over having no cue at all. ${ }^{(19)}$ For the mnemonic to be effective, it should only be used periodically. ${ }^{(19)}$

In conclusion, the results of the present study support the use of the TWED checklist to facilitate metacognition in clinical 
decision-making. Despite the limitations of this preliminary study, the results support further investigation into this tool to aid metacognition.

\section{ACKNOWLEDGEMENT}

The authors would like to thank Prof Patrick Croskerry, Dalhousie University, Halifax, Nova Scotia, Canada, for his advice in the initial conception of the TWED checklist.

\section{REFERENCES}

1. Schneider W, Shiffrin RM. Controlled and automatic human information processing: I. Detection, search and attention. Psychol Rev 1977; 84:1-66.

2. Shiffrin RM, Schneider W. Controlled and automatic human information processing: II. Perceptual learning, automatic attending, and a general theory. Psychological Review 1977; 84:127-90.

3. Croskerry P. A universal model of diagnostic reasoning. Acad Med 2009; 84:1022-8.

4. Stanovich KE, Toplak ME. Defining features versus incidental correlates of Type 1 and Type 2 processing. Mind Soc 2012; 11:3-13.

5. Evans JS, Stanovich KE. Dual-process theories of higher cognition: advancing the debate. Perspect Psychol Sci 2013; 8:223-41.

6. Croskerry P, Petrie DA, Reilly JB, Tait G. Deciding about fast and slow decisions. Acad Med 2014; 89:197-200.

7. van Merriënboer JJG. Perspectives on problem solving and instruction. Comput Educ 2013; 64:153-60.

8. Stanovich KE. What intelligence tests miss: the psychology of rational thought. New Haven: Yale University Press; 2009.
9. Croskerry P, Singhal G, Mamede S. Cognitive debiasing 1: origins of bias and theory of debiasing. BMJ Qual Saf 2013; 22 Suppl 2:ii58-ii64.

10. Arnott D. Cognitive biases and decision support systems development: a design science approach. ISJ 2006; 16:55-78.

11. Croskerry $P$. The importance of cognitive errors in diagnosis and strategies to minimize them. Acad Med 2003; 78:775-80.

12. Croskerry P, Singhal G, Mamede S. Cognitive debiasing 2: impediments to and strategies for change. BMJ Qual Saf 2013; 22 Suppl 2:ii65-ii72.

13. Graber ML, Kissam S, Payne VL, et al. Cognitive interventions to reduce diagnostic error: a narrative review. BMJ Qual Saf 2012; 21:535-57.

14. Graber M. Metacognitive training to reduce diagnostic errors: ready for prime time? Acad Med 2003; 78:781.

15. Croskerry P. From mindless to mindful practice--cognitive bias and clinical decision making. N Engl J Med 2013; 368:2445-8

16. Croskerry P. ED cognition: any decision by anyone at any time. CJEM 2014; 16:13-9.

17. Norman G. Dual processing and diagnostic errors. Adv Health Sci Educ Theory Pract 2009; 14 Suppl 1:37-49.

18. Gollwitzer PM. Implementation Intentions: Strong Effects of Simple Plans. Am Psychol 1999; 54:493-503.

19. McDaniel MA, Einstein GO, Graham T, Rall E. Delaying execution of intentions: overcoming the costs of interruptions. Appl Cognitive Psych $2004 ; 18: 533-47$

20. Gibson HA. Using mnemonics to increase knowledge of an organizing curriculum framework. Teach Learn Nurs 2009; 4:56-62.

21. Sibbald M, de Bruin AB, Cavalcanti RB, van Merrienboer JJ. Do you have to re-examine to reconsider your diagnosis? Checklists and cardiac exam. BMJ Qual Saf 2013; 22:333-8.

22. De Amici D, Klersy C, Ramajoli F, Brustia L, Politi P. Impact of the Hawthorne effect in a longitudinal clinical study: the case of anesthesia. Control Clin Trials 2000; 21:103-14. 


\section{APPENDIX 1}

\begin{tabular}{|c|c|c|c|c|}
\hline Case & $\begin{array}{l}\text { Apparent } \\
\text { diagnosis }\end{array}$ & Potential cognitive bias & $\begin{array}{l}\text { Second (more serious) } \\
\text { diagnosis }\end{array}$ & How TWED checklist helps \\
\hline 1 & $\begin{array}{l}\text { Anxiety disorder } \\
\text { with possible } \\
\text { secondary } \\
\text { gain, acute } \\
\text { gastroenteritis, } \\
\text { food poisoning }\end{array}$ & $\begin{array}{l}\text { Search satisficing: Participants may be satisfied with the } \\
\text { diagnosis of stress-related anxiety disorder and satisfied } \\
\text { that the patient was responsive to intravenous hydration for } \\
\text { acute gastroenteritis. Hence, they do not seek an alternative } \\
\text { diagnosis. }\end{array}$ & $\begin{array}{l}\text { Acute myocardial ischaemia } \\
\text { secondary to cocaine } \\
\text { (sympathomimetic) } \\
\text { intoxication }\end{array}$ & $\begin{array}{l}T=\text { What is the life/limb threat in this case? } \\
\text { History of cocaine ingestion and chest discomfort should alert the participant } \\
\text { to the possibility of sympathomimetic-induced myocardial ischaemia. } \\
D=\text { What are the dispositional factors influencing your decision? } \\
\text { Emotive disposition: the pestering for a medical leave certificate may elicit } \\
\text { a repulsive response from the participant. }\end{array}$ \\
\hline 2 & $\begin{array}{l}\text { Stress-related } \\
\text { tension headache }\end{array}$ & $\begin{array}{l}\text { Availability bias: the relationship between neck pain and } \\
\text { meningism (irrespective of cause) may not readily come to mind } \\
\text { if the participant has not seen or read about meningism. } \\
\text { Search satisficing: Participants may be satisfied with the } \\
\text { pain score improvement after medications and do not seek an } \\
\text { alternative diagnosis. }\end{array}$ & $\begin{array}{l}\text { Meningism, secondary } \\
\text { subarachnoid haemorrhage }\end{array}$ & $\begin{array}{l}T=\text { What is the life/limb threat in this case? } \\
\text { The mere fact that the patient presents to the department in the early hours } \\
(3 \mathrm{am}) \text { should alert the participant that this could be something more sinister } \\
\text { than a tension headache. The quality/nature as well as the severity of the } \\
\text { headache, which was worse compared to previous headaches she experienced, } \\
\text { should also alert the participant that this could be a red flag. } \\
W=\text { What else? What if } I \text { am wrong? } \\
\text { The fact that the patient developed neck pain the following morning is a red } \\
\text { flag for meningism. }\end{array}$ \\
\hline 3 & $\begin{array}{l}\text { Acute coronary } \\
\text { syndrome }\end{array}$ & $\begin{array}{l}\text { Search satisficing: Participants may be satisfied with the } \\
\text { diagnosis of acute coronary syndrome 'inherited' from the } \\
\text { paramedic who performs the triage, hence do not seek an } \\
\text { alternative diagnosis. } \\
\text { Availability bias: Participants who only look at the absolute } \\
\text { value of a vital sign, and are not in the habit of analysing } \\
\text { its trend/dynamics by comparing the reading before and } \\
\text { after may miss the significant drop in blood pressure. } \\
\text { Participants who do not review the medications the patient } \\
\text { is taking (e.g. beta-blocker) may miss the masking effect of } \\
\text { beta-blocker on tachycardic manifestation. }\end{array}$ & $\begin{array}{l}\text { Perforated viscus with acute } \\
\text { haemorrhage/peptic ulcer } \\
\text { bleeding }\end{array}$ & $\begin{array}{l}T=\text { What is the life threat? } \\
\text { Epigastric tenderness + hypotension = the need to rule out perforated viscus/ } \\
\text { peptic ulcer bleeding } \\
W=\text { What else? What if } I \text { am } \text { wrong? } \\
\text { The absence of appropriate tachycardia does not necessarily mean that the } \\
\text { patient is not having acute haemorrhage, as he is taking beta-blocker. }\end{array}$ \\
\hline 4 & $\begin{array}{l}\text { Healed } \\
\text { compression spinal } \\
\text { fracture with } \\
\text { osteophytes }\end{array}$ & $\begin{array}{l}\text { Anchoring and confirmation bias: Participants who have } \\
\text { anchored the diagnosis of healed compression fracture of the } \\
\text { spine tend to associate the accident with the healed fracture as } \\
\text { the cause of the current back pain. } \\
\text { Search satisficing: Participants may be satisfied with the diagnosis } \\
\text { offered by more authoritative personnel (i.e. the registrar in charge). } \\
\text { Availability bias: Participants who are not in the habit of } \\
\text { actively trying to correlate the clinical finding with the apparent } \\
\text { abnormality found on the radiograph may miss the discrepancy } \\
\text { between the sensory loss at the level of umbilicus (T10) with } \\
\text { the L1 findings on the radiograph. }\end{array}$ & $\begin{array}{l}\text { Acute progressive paraplegia } \\
\text { from T10 level that } \\
\text { demands further in-hospital } \\
\text { investigations }\end{array}$ & $\begin{array}{l}W=\text { What else? What if I am wrong? } \\
\text { The discrepancy between clinical finding and radiologic finding should } \\
\text { demand a re-assessment. } \\
\boldsymbol{E}=\boldsymbol{D} \boldsymbol{I} \mathbf{I} \text { have sufficient evidence to support this diagnosis? } \\
\text { Again, if the participants slow down and attempt to correlate the clinical } \\
\text { findings with the radiologic findings, there is no evidence to suggest that the } \\
\text { current complaints of the patient are due to the L1 lesion. }\end{array}$ \\
\hline 5 & Mild head injury & $\begin{array}{l}\text { Search satisficing: Participants may be satisfied with the } \\
\text { negative findings on skull radiography and her full Glasgow } \\
\text { Coma Scale scores and hence do not seek an alternative } \\
\text { diagnosis. } \\
\text { Confirmation bias: Participants who have anchored the } \\
\text { diagnosis of mild head injury may look for a negative skull } \\
\text { radiograph to confirm their suspicion. }\end{array}$ & $\begin{array}{l}\text { Headache and repeated } \\
\text { episodes of vomiting are } \\
\text { red flags to perform head } \\
\text { computed tomography, } \\
\text { especially for an elderly } \\
\text { patient }\end{array}$ & $\begin{array}{l}T=\text { What is the life threat? } \\
\text { Headaches + repeated episodes of vomiting + physiological/anatomical } \\
\text { changes of the elderly = red flags for traumatic intracranial bleeding }\end{array}$ \\
\hline
\end{tabular}




\section{APPENDIX 2}

\section{Case scenario 1}

A man in his 20s presents to an emergency department complaining of acute shortness of breath and central chest discomfort for three hours prior to arrival. He appears anxious, sweaty and feverish. He had two episodes of diarrhoea and vomiting the night before, and claims that it could possibly be due to the curry noodle that he ate. He says that his assignment is due in three days' time and requests that the doctor gives him one day of medical leave.

His initial vital signs are: blood pressure $140 / 90 \mathrm{mmHg}$; pulse rate 140 beats/minute; temperature $39^{\circ} \mathrm{C}$; and respiratory rate 30 breaths/minute. The paramedic at the triage counter tags him with a diagnosis of 'acute gastroenteritis' and treats him with $600 \mathrm{cc}$ of normal saline $0.9 \%$.

About half an hour later, when asked by the attending doctor, the patient says that he had a drink with his friends at a nightclub "just to unwind from the stress of the job". He admits to have consumed cocaine pills during the party. He also admits that he consumes cocaine "on a regular basis".

Except for mild chest discomfort, he says that he feels much better after the intravenous hydration and impatiently pesters the doctor to discharge him with one day of medical leave. The doctor finds no significant findings on physical examination.

\section{Questions:}

1. If you were the attending doctor, would you have discharged him with a one-day medical leave certificate? Why or why not? (Total marks: 7)

Marking scheme:

- Not ready for discharge (1 mark)

- Give reason(s): e.g. persistent chest pain (1 mark), need to rule out coronary event (1 mark)

- Give rationale/explanation: because of ingestion of cocaine (1 mark), cocaine results in catecholamine surge (1 mark); resulting in sympathetic over-activity and coronary artery vasoconstriction and spasm (1 mark)

- What needs to be done: at least electrocardiography (1 mark)

Note: No mark to be rewarded for this question if the student agrees to discharge the patient at this juncture without further investigation.

\section{List the diagnoses you should consider for this patient. (Total marks: 3 )}

Marking scheme:

- Myocardial ischaemia/infarction (1 mark)*

- Acute gastroenteritis (1 mark)

- Anxiety disorder/malingering (1 mark)

*May include other diagnosis that could be reasonably considered in this case. 'Myocardial ischaemia/infarction' must be included as an answer; otherwise, a maximum of 2 marks will be awarded. 